\title{
Comunicação
}

[Communication]

\section{Taxa de infestação por ácaro Varroa destructor em apiários sob georreferenciamento}

\author{
[Rate of infestation by Varroa destructor in apiaries under geoprocessing] \\ G.L. Bacha Júnior, A.S. Felipe-Silva, P.L.L. Pereira \\ Escola de Veterinária - UFMG \\ Caixa Postal 567 \\ 30123-970 - Belo Horizonte, MG
}

\begin{abstract}
A apicultura destaca-se por ser uma das poucas atividades zootécnicas causadoras de baixos impactos ambientais e que, ao mesmo tempo, proporciona rápido retorno do capital investido. Os dados gerados pelo geoprocessamento constituem uma ferramenta de uso imprescindível em apicultura, pois facilitam a avaliação espacial de áreas onde estão localizados os apiários e a determinação das distâncias ótimas entre eles, além de levantamento de floradas, monitoramento de densidade da população apícola e a correção do manejo relacionado à localização inadequada de colmeias. Dessa forma, a utilização do geoprocessamento é útil para delimitar áreas com alta concentração de enxames, detecção e monitoramento de doenças e pragas, além de permitir, no futuro, o monitoramento de terras de cultura que utilizem agrotóxicos, evidenciando fator de risco para as abelhas e para o ser humano, por meio do consumo de produtos apícolas contaminados.
\end{abstract}

O objetivo deste trabalho foi avaliar, por meio de georreferenciamento, a taxa de infestação de apiários de produção, pelo ácaro Varroa destructor, em função da existência ou não de sobreposição de nichos de forrageamento das colmeias. Definiram-se, com o auxílio do georreferenciamento dos apiários, as áreas com sobreposição e sem sobreposição de nichos de forrageamento. Abelhas adultas foram coletadas nesses locais, com o objetivo de avaliar a taxa de infestação por Varroa destructor e verificar se a sobreposição exerceu influência sobre a taxa de infestação do ácaro.

Recebido em 14 de novembro de 2008

Aceito em 30 de setembro de 2009

E-mail: gabriel_6713@hotmail.com
A área escolhida para o presente estudo foi a microrregião de Viçosa (Fig. 1), especificamente os municípios de Guaraciaba (núcleo 1), Paula Cândido (núcleo 2) e Piranga (núcleo 3), tendo, respectivamente, as seguintes coordenadas: lat. $20^{\circ} 35^{\prime} 34,87243$ "e long. $-42^{\circ} 58^{\prime} 54,57182^{\prime \prime}$; lat. $20^{\circ} 48^{\prime} 43,07741^{\prime \prime}$ e long. $-42^{\circ} 54^{\prime} 55,21445^{\prime \prime}$; lat. $-20^{\circ} 37^{\prime} 17,72686^{\prime \prime}$ long. $-43^{\circ} 17^{\prime} 10,91333^{\prime \prime}$. A microrregião de Viçosa está contida na mesorregião da Zona da Mata mineira, uma das 12 mesorregiões do Estado de Minas Gerais, situada junto à divisa dos Estados do Rio de Janeiro e do Espírito Santo. Localiza-se no sudeste do Estado, em região caracteristicamente montanhosa. A região faz parte das Terras Altas Brasileiras, divisão geopolítica denominada de Zona da Mata. Os solos da região apresentam-se com baixa fertilidade, sendo classificados como latossolo vermelho-amarelo e latossolo amarelo, predominantemente (Valverde, 1958).

Optou-se pelos apiários trabalhados, em função de prévio georreferenciamento e geração de mapas que permitiram a visualização da distribuição dos apiários e a identificação de dois núcleos com sobreposição de nichos e excesso populacional e um núcleo com um apiário sem sobreposição. Definiu-se sobreposição a partir do traçado de uma circunferência com raio de $1000 \mathrm{~m}$. Dos 128 enxames vistoriados, foram coletadas 57 amostras de abelhas para a determinação da taxa de infestação pelo ácaro. A taxa de infestação foi verificada utilizando-se protocolo apresentado por Stort et al. (1981) e De Jong e Gonçalves (1981), modificada por Message (1983). 


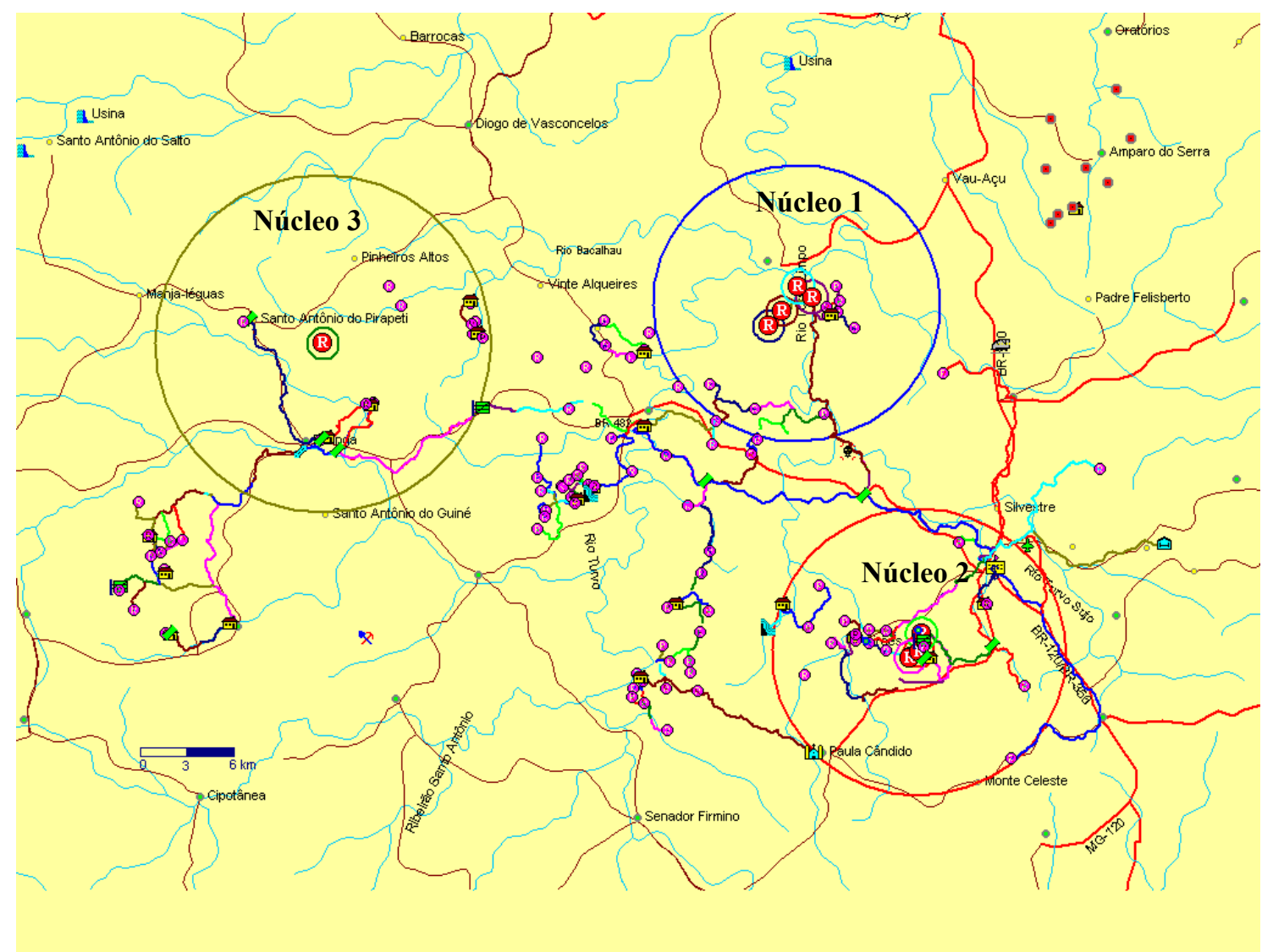

Figura 1. Áreas de coleta de abelhas segundo os núcleos de criação.

Utilizou-se um aparelho de GPS Garmin 76S para a coleta dos pontos de georreferenciamento dos apiários, das sedes dos apicultores e das trilhas para a localização dos apiários. Por questões de segurança e privacidade dos apicultores, as trilhas foram omitidas e os pontos mostrados em mapas sem as referências de localização geográfica (latitude/longitude ou UTM).

Ao redor dos apiários foi traçado um raio de $1000 \mathrm{~m}$ e foi estabelecido um círculo ao redor do ponto inicial, com o intuito de se verificar a sobreposição dos apiários e, desta forma, definir as áreas de sobreposição de cada apiário e o número de colmeias por apiário.

Para a geração dos mapas, utilizou-se o programa Trackmaker - Versão 4.0. As ferramentas do programa, pincel e elipse, foram utilizadas a fim de se traçar o raio em torno dos apiários, correspondentes às áreas de forrageamento de cada apiário, bem como as áreas de sobreposição entre eles.
Os resultados da taxa de infestação por Varroa destructor são apresentados na Tab. 1.

Os resultados dos núcleos 1 e 2 demonstraram infestação relativamente alta, acima dos resultados descritos por Message (1983); Correa-Marques (2000) e Funari et al. (2002). Esta situação sugere que a sobreposição das áreas de forrageamento das colmeias pode estar associada à ocorrência da varroatose. A colônia com menor taxa de infestação foi de $4,7 \%$, e a com maior índice de infestação de $20,2 \%$. As médias do núcleo 1 foram praticamente o dobro das taxas descritas pelos autores já mencionados. Entretanto, no terceiro núcleo, onde não ocorreu nenhuma sobreposição entre apiários, a média foi semelhante às verificadas na literatura consultada. A menor taxa observada neste núcleo foi de $0,41 \%$, e a maior de $10,6 \%$. Pode-se inferir a possibilidade de o fator densidade populacional estar associado aos níveis de infestação do ácaro. $\mathrm{O}$ georreferenciamento permitiu avaliar áreas com menor ou maior risco epidemiológico para 
Varroa destructor, tornando-se uma ferramenta de grande importância para realização e monitoramento de estudos sobre patologias e pragas que afetam a apicultura. A taxa de infestação foi três vezes maior em apiários com áreas de sobreposição de forrageamento comparados àqueles sem sobreposição.

Tabela 1. Taxa de infestação média por Varroa destructor nos núcleos avaliados

\begin{tabular}{cccc}
\hline & Apiário & Taxa de infestação (\%) & Média total (\%) \\
\hline \multirow{2}{*}{ Núcleo 1 } & Sobradinho & 9,9 & 10,96 \\
& Sumidouro & 12,75 & \\
& Fone & 10,22 & \multirow{2}{*}{ Núcleo 26} \\
& Lúcia & 9,27 & \\
\hline & Toninho & 10,19 & 3,32 \\
\hline
\end{tabular}

O georreferenciamento forneceu parâmetros para escolha de amostras nos apiários, pois, com o auxílio dele, visualizaram-se as áreas com e sem sobreposição, e permitiu, também, a melhor distribuição de apiários localizados em áreas de excessiva sobreposição, para um melhor controle parasitário das abelhas. O programa
TRACKMAKER mostrou-se eficaz na execução de mapas iniciais, sendo possível um melhor planejamento da logística de trabalho na atividade apícola.

Palavras-chave: abelha, apiário, ácaros, geoprocessamento

\section{ABSTRACT}

The rate of infestation of Varroa destructor was investigated in 128 swarms of bees, distributed in three distinct apiaries: with (two) and without (one) superposition of the visualized feeding areas, identified by geoprocessing analysis. A higher infestation rate was observed where superposition in the feeding areas was observed (averages $11.0 \%$ and $9.3 \%$ ) in contrast with the swarms in the apiary where there were no common feeding areas (3.3\%). This suggests that superposition of visualized feeding areas is associated with the varroatosis occurrence and that it favors the enhancement of the mite infestation rate in the beehives.

Keywords: bee, apiary, mites, geoprocessing

\section{REFERÊNCIAS BIBLIOGRÁFICAS}

CORRÊA-MARQUES, M.H. Reprodução do ácaro Varroa jacobsoni em colônias de abelhas africanizadas no Brasil. 2000. 113f. Tese (Doutorado) - Universidade de São Paulo, Ribeirão Preto, SP.

DE JONG, D.; GONÇALVES, L.S. The Varroa problem in Brazil. Am. Bee J., v.121, p.186-189, 1981

FUNARI, S.R.C.; ARAUCO, E.M.R.; ALBARRACÍN, V.N. et al. Comportamento higiênico e taxa de infestação do ácaro Varroa jacobsonii em abelhas Apis mellifera africanizas e cárnicas. In: CONGRESSO BRASILEIRO DE APICULTURA, 14., 2002, Campo Grande, MS. Abstracts do CONBRAPI 2002. Campo Grande, MS: CBA, 2002. p.34.

MESSAGE, D. Patologia apícola. Inf. Agropec., v.106, p.71-76, 1983.

STORT, A.C.; GONÇALVES, L.S.; MALASPINA, O. et al. Study on sineacar effectiveness in controlling Varroa jacobsoni. Apidologie, v.12, p.289-297, 1981.

VALVERDE, O. Estudo regional da Zona da Mata de Minas Gerais. Rev. Bras. Geogr., v.20, p.1-82, 1958. 